\title{
Application of Virtual Reality in the Teaching of Interior Design
}

\author{
Xiao Han* \\ Chongqing Energy College, Chongqing 402260, China \\ *Corresponding author: Xiao Han, 380503504@qq.com
}

\begin{abstract}
With the rapid development of computer technology, a new technology - virtual reality has arisen at this historical moment. This technology mainly creates a real scene through simulation so as to reflect the changing form of objects. As a complex art form, the characteristics of interior design cannot be displayed only through pictures and words but with the effective application of virtual reality, the development of interior design can be promoted. This article mainly analyzes the current teaching situation of interior design and puts forward specific application strategies of virtual reality in the teaching of interior design, which have guiding significance in improving the teaching effect of interior design.
\end{abstract}

Keywords: Virtual technology; Interior design; Teaching application

Publication date: September 2021; Online publication: September 30, 2021

\section{Introduction}

In recent years, with the rapid development of internet technology, the advent of the big data era has greatly influence people's lives. Virtual reality is the key development direction of modern simulation technology. It can integrate various information to form three-dimensional dynamic video images. This technology is widely used in the teaching of interior design. The application of virtual reality in indoor teaching does not only create a good design space for students, but also truly reproduce the design scene to ensure a more interactive environment for designing.

\section{Analysis on the current teaching situation of interior design}

With the rapid wave of the teaching reform, the teaching means and methods of interior design courses have been reformed and innovated. However, through relevant investigations, results have shown that in the teaching of interior design, some teachers still use a single multimedia courseware. This teaching method does not meet the needs of students' professional learning.

At present, the teaching methods of interior design courses have certain limitations. People are familiar with the teaching methods of network courseware, flash courseware, and audio courseware. Although these teaching methods can attract students' attention and mobilize their learning enthusiasm, they have several disadvantages in terms of practical application. For example, the frequently used multimedia-assisted teaching courseware can only realize the display of a single picture or video in the content level design; it is at a disadvantage in the display of three-dimensional space, which hinders the cultivation of students' visual thinking and spatial thinking ability ${ }^{[1]}$. At the same time, students are spoon-fed with professional knowledge, but they lack innovative design ideas and inspiration. This makes it difficult for them to understand professional knowledge and improve their professional skills. 


\section{Effective application strategies of virtual reality in the teaching of interior design}

\subsection{Changing traditional teaching ideas}

In the past, teachers would hold dominance during classroom teaching while passing on the knowledge contents from textbooks to their students. In addition, the teaching syllabus, teaching contents, and teaching plans highlight the teachers' control. Students themselves are in a passive state during the whole process, which is not conducive to the improvement of their abilities over time. However, with the guiding ideology of modern teaching theory, virtual reality is used in interior design courses to carry out teaching activities, change traditional teaching ideas, give full play to the main role of students, fully understand students' personalities, and guide them to actively learn and explore.

\subsection{Promoting the transformation of teaching content composition system}

In interior design teaching, virtual reality and multimedia teaching are integrated to enrich and diversify the teaching contents. Teachers use virtual reality to adjust the teaching contents, process them into specialized teaching materials, and publish them on the network platform so that students can learn and understand the latest developments and development trends in the field of design anytime and anywhere. Teachers should take the theoretical basis of current textbooks as the editing element of network teaching materials to adjust and improve the content composition of online teaching materials in combination with design ideas and practical skills in the professional field. The combination of theoretical knowledge teaching contents and interior design practical cases is conducive for students to fully grasp the theoretical knowledge contents. Teachers should use a variety of teaching forms to stimulate students' interest and enthusiasm in learning as well as encourage them to actively participate in learning ${ }^{[2]}$.

\subsection{Application of virtual reality in scheme design}

Scheme design is an extremely important aspect in interior design. The effective application of virtual reality in this link will help achieve twice the results with half the effort. In the teaching process of interior design, students should be separated into different groups for learning and analyzing to decide on their own design style and theme content within their groups. Teachers should encourage students to use virtual reality to appreciate the changes of the indoor space more directly for them to clarify their own design direction and ideas. Secondly, virtual reality should also be used in the teaching of interior design so that students can accurately determine the location of doors, windows, and various furnishings as if they are present at the scene. For students who have just begun their journey in interior design, they should use virtual reality to meet the actual needs of customers through training and experience in the training environment.

\subsection{Application of virtual reality in the display of interior decoration}

Virtual reality technology plays an important role in the effect display of interior decoration. Through virtual reality, different spaces can be decorated and designed while different scenes can be presented dynamically. Students can then watch and experience through the computer network system. This will save investments in the construction of a training base and teachings can be realized through the network. In the traditional way of interior design teaching, most students would only use drawings to display design schemes, which affects students' creativity ${ }^{[3]}$. However, with the wide application of virtual reality as well as the characteristics of the integration of computer network information technology and virtual reality, students' design concept can be fully displayed by using three-dimensional dynamic space effect, thus forming a virtual simulation space. In this way, students can intuitively appreciate the design effect from the design theme setting. This will eventually reduce communication problems between the designers and their clients. By creating a three-dimensional dynamic space, clients would be able to experience a real 
feeling, and in that process, they will be able to provide suggestions at any time. They have the options of changing the tiles, floor, wall color, placement of furniture and home appliances, or even choose different styles of decorations at will to perfect the interior decoration style and overall effect.

\subsection{Rational use of teaching tools}

In the process of interior design teaching, virtual reality is applied to create an interactive teaching environment by using a program software. According to specific teaching requirements, the angle and area of an interior design scene are controlled at will and various objects in the scene are reasonably moved in order to achieve the objectives of teaching. Under the reasonable use of virtual reality, students can actively participate in the teaching process, and in combination with visual teaching materials, students' senses can be stimulated. Teachers should take full consideration of students' behavioral characteristics and cognitive ability in planning the teaching contents. The standard courseware that combines theory and virtual situation is realized by means of multimedia-assisted virtual reality technology. Students can then watch the courseware anytime and anywhere to develop divergent thinking.

\section{Advantages of the application of virtual reality in the teaching of interior design}

\subsection{Helping students to understand professional knowledge through intuitive feelings}

In the actual teaching scenario of interior design, teachers often share their own designed works with their students. There are many skills and materials that students are not able to understand from these works, thus facing difficulties in learning them. In that case, teachers would often look for relevant teaching resources and spend a lot of time to explain them. However, students would only watch and listen passively during the whole process but still fail to fully absorb and digest the information that has been shared. With the application of virtual reality, students can repeatedly watch the contents and structures that they do not understand. Through intuitive and visual feelings, students can then experience a dynamic learning environment. This would help solve the difficulties in learning and promote their understanding of professional knowledge ${ }^{[4]}$.

\subsection{Enhancing students' core competitiveness in the industry}

Virtual reality has established a communication bridge between designers and users. Designers can accurately convey design concepts and schemes to their clients based on their requirements. In view of the current development situation, interior designers who are able to master the virtual reality technology account for the inevitable development trend of the society. In addition, the industry would favor and take an interest in these designers. On the basis of basic professional knowledge of interior design, students can also master the skills of panorama production by virtual reality and stand out in the industry.

\section{Conclusion}

With the continuous development of science and technology, there are several disadvantages in previous interior design teaching curriculums and methods. However, the effective use of virtual reality in the teaching of interior design can improve these problems. The application of virtual reality in every link of interior design teaching enables students to intuitively and vividly experience, deepen their understanding and memory of professional knowledge, improve their design skills and aesthetic ability in a relaxed and pleasant imitation of real scenes, as well as create favorable conditions for students' future professional growth. 


\section{Disclosure statement}

The author declares that there is no conflict of interest.

\section{References}

[1] Zhang Q, 2021, Research on the Application of VIRTUAL Reality Technology in Interior Design Course Teaching. West Leather, 43(10): 123-124.

[2] Pan Y, 2020, Innovative Application of Virtual Reality Technology in Interior Design Teaching. Business Information, (19): 228.

[3] Fan L, 2021, Discussion on the Application of Virtual Reality Technology in Interior Design and Decoration. China Housing Facilities, (4): 70-71.

[4] Xue H, Fan L, Li Z, 2021, Application of Virtual Reality Technology in Residential Space Interior Design. Anhui Architecture, 28(2): 92-101. 